ISSN 2179-6750

\title{
Perfil, qualidade de vida e uso de medicamentos em pacientes renais crônicos submetidos à hemodiálise
}

Emanuele Gama Dutra-Costa, Daniela Bissoli Uliana, Pâmela Schettino Souza, Valéria Oliveira Cassiano, Juliana Santiago-Silva

\section{Resumo}

Atualmente vem aumentando o número de pessoas que são diagnosticadas com Doença Renal Crônica (DRC) e que são submetidas à hemodiálise. Sabe-se que a qualidade de vida dessas pessoas vem a influenciar na ocorrência dessa doença, visto que, cada vez mais, hábitos de vida menos saudáveis vem contribuindo para isso. Avaliar o perfil, a qualidade de vida, e o uso de medicamentos em pacientes renais crônicos submetidos a tratamento em uma clínica de hemodiálise localizada na região da zona da Mata Mineira e a atuação do farmacêutico neste contexto. Foi realizada uma pesquisa com 73 pacientes que aceitaram participar voluntariamente da pesquisa, assinando o Termo de Consentimento Livre Esclarecido (TCLE). Como instrumento foi utilizado um questionário com a finalidade de caracterizar e analisar os pacientes quanto à idade, sexo, estado civil, escolaridade, tempo de tratamento de hemodiálise, atividades comprometidas pelo tratamento, uso de medicamentos, entre outros. Entre os pacientes com DRC investigados, houve a prevalência de indivíduos adultos, casados, com baixa escolaridade e aposentados. Entretanto, não foi encontrada diferença significante entre o sexo. A maioria faz hemodiálise há mais de cinco anos e relata interferências do tratamento na vida profissional e pessoal. Verificou-se neste estudo que a maioria dos pacientes participantes da pesquisa realiza a politerapia e por vezes descontinua o tratamento por conta própria. Medidas de acompanhamento multidisciplinares juntamente aos pacientes submetidos à hemodiálise são necessárias, auxiliando na adesão ao tratamento e melhoria da condição de vida destes.

Descritores: Doença Renal Crônica; Nefropatia; Hemodiálise. 